\title{
“Avaliação da Resistência da União Dentina-Adesivo Utilizando Diferentes Condicionamentos Dentinários"
}

\author{
Maicon Sebold (IC), Carolina B. André (PG), Marcelo Giannini (PQ).
}

\section{Resumo}

O presente estudo teve como objetivo avaliar a resistência da união dentina-resina, utilizando-se diferentes condicionamentos. Vinte e quatro terceiros molares tiveram o esmalte oclusal removido com disco diamantado para exposição da dentina, a qual foi abrasionada com lixas de SiC (\#600). Em seguida os dentes foram aleatoriamente divididos em 3 grupos experimentais $(n=8)$ : condicionamento com ácido fosfórico 37\% (15s), EDTA 0,1 M (60s) e EDTA 0,5 M (120s). O adesivo (XP Bond, Dentsply) foi aplicado e três incrementos de resina composta (EsthetX, Dentsply) de $2 \mathrm{~mm}$ cada foram inseridos na superfície dentinária, sendo cada um fotoativado individualmente. Os dentes restaurados foram seccionados transversalmente para se obter espécimes para o ensaio de microtração ( $1 \mathrm{~mm}^{2}$ na secção transversal). Metade dos espécimes foi testada em máquina universal de ensaio (EZ Test, Shimadzu) após 24 horas, enquanto a outra metade foi testada após armazenamento em saliva artificial por 1 ano. $O$ padrão de fratura das superfícies dos espécimes foi analisado em microscópio eletrônico de varredura (MEV). Os resultados de resistência de união, após 24 hrs e 1 ano de armazenamento foram, respectivamente (em MPa): ácido fosfórico 37\%: 37,3(7,7) / 33,9(6,7); EDTA 0,1 M: 14,7(7,3) / 15,1(10,1); EDTA 0,5 M: 25,1(7,7) / 21,1(14,1). Os padrões de fratura predominantes foram: ácido fosfórico $37 \%$ e EDTA $0,5 \mathrm{M}$ : falha mista; EDTA 0,1 M: falha adesiva entre a dentina e o agente de união. O condicionamento da dentina com EDTA, independente da concentração resultou em menor resistência de união quando comparado ao ataque com ácido fosfórico.

Palavras Chave: dentina, ataque ácido dentário, EDTA.

\section{Introdução}

O condicionamento da dentina com ácido fosfórico tem sido amplamente utilizado para nas restaurações de resina composta. Contudo, estudos tem demonstrado que o condicionamento dentinário com ácido pode desencadear na ativação das metaloproteinases da matriz, enzimas que provocam a degradação da camada híbrida a longo prazo. Tem-se sugerido o uso do EDTA como agente de condicionamento dentinário, pois essa substância poderia promover resistência de união dente-restauração satisfatória, sem provocar a ativação das metaloproteinases. O presente estudo teve como objetivo avaliar a resistência da união dentinaresina, utilizando diferentes condicionamentos.

\section{Resultados e Discussão}

As médias de resistência de união dos grupos estão apresentadas na Tabela 1 e os padrões de fratura mais característicos de cada grupo são mostrados na Figura 1.

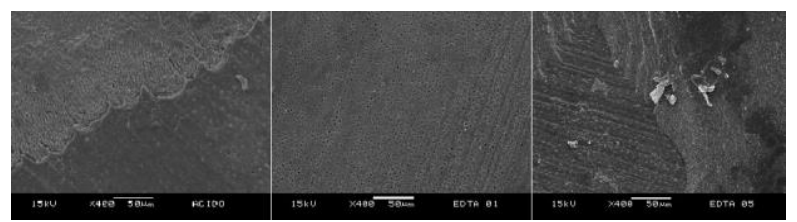

Figura 1. Imagens dos padrões de fratura predominantes em cada grupo obtidas em MEV.
Tabela 1. Média (desvio padrão) em função do condicionamento dentinário (em MPa).

\begin{tabular}{|l|c|c|}
\hline \multirow{2}{*}{ Tratamentos } & \multicolumn{2}{|c|}{ Tempo } \\
\cline { 2 - 3 } & 24 horas & 1 ano \\
\hline Ácido Fosfórico & $37,3(7,7) \mathrm{Aa}$ & $33,9(6,7) \mathrm{Aa}$ \\
\hline EDTA 0,1 M & $14,7(7,3) \mathrm{Ab}$ & $15,1(10,1) \mathrm{Ab}$ \\
\hline EDTA 0,5 M & $25,1(7,7) \mathrm{Ab}$ & $21,1(14,1) \mathrm{Ab}$ \\
\hline
\end{tabular}

Médias seguidas de letras distintas (maiúsculas na horizontal e minúsculas na vertical) diferem entre si $(p \leq 0,05)$.

\section{Conclusões}

O condicionamento da dentina com EDTA 01,M ou $0,5 \mathrm{M}$, resultou em menor resistência de união quando comparado ao ácido fosfórico.

\section{Agradecimentos}

\section{PIBIC - CNPq}

\footnotetext{
${ }^{1}$ Nishitani Y, Yoshiyama M, Wadgaonkar B, Breschi L, Mannello F, Mazzoni A, Carvalho RM, Tjäderhane L, Tay FR, Pashley DH. Eur J Oral Sci 2006; 114(2): 160-166.

${ }^{2}$ Breschi L, Cammelli F, Visintini E, Mazzoni A, Vita F, Carrilho M, et al. J Adhes Dent. 2009; 11(3):191-98.
} 